\title{
Acute and Chronic Role of Nitric Oxide, Renin-Angiotensin System and Sympathetic Nervous System in the Modulation of Calcium Sensitization in Wistar Rats
}

\author{
A. BRUNOVÁ ${ }^{1}$, M. BENCZE ${ }^{1}$, M. BEHULIAK ${ }^{1}$, J. ZICHA ${ }^{1}$ \\ ${ }^{1}$ Institute of Physiology, Czech Academy of Sciences, Prague, Czech Republic
}

Received May 20, 2015

Accepted June 15, 2015

\section{Summary}

Principal vasoactive systems - renin-angiotensin system (RAS), sympathetic nervous system (SNS), nitric oxide (NO) and prostanoids - exert their vascular effects through the changes in calcium levels and/or calcium sensitization. To estimate a possible modulation of calcium sensitization by the above vasoactive systems, we studied the influence of acute and chronic blockade of particular vasoactive systems on blood pressure (BP) changes elicited in conscious normotensive rats by acute dose-dependent administration of Rho-kinase inhibitor fasudil. Adult male chronically cannulated Wistar rats were used throughout this study. The acute inhibition of NO synthase (NOS) by L-NAME enhanced BP response to fasudil, the effect being considerably augmented in rats deprived of endogenous SNS. The acute inhibition of prostanoid synthesis by indomethacin modified BP response to fasudil less than the acute NOS inhibition. The chronic NOS inhibition caused moderate BP elevation and a more pronounced augmentation of fasudilinduced BP changes compared to the effect of acute NOS inhibition. This indicates both short-term and long-term NOdependent attenuation of calcium sensitization. Long-term inhibition of RAS by captopril caused a significant attenuation of BP changes elicited by fasudil. In contrast, a long-term attenuation of SNS by chronic guanethidine treatment (in youth or adulthood) had no effect on BP response to fasudil, suggesting the absence of SNS does not affect calcium sensitization in vascular smooth muscle of normotensive rats. In conclusion, renin-angiotensin system contributes to the long-term increase of calcium sensitization and its effect is counterbalanced by nitric oxide which decreases calcium sensitization in Wistar rats.

\section{Key words}

Blood pressure • Calcium sensitization • Rho-kinase • Nitric oxide - Renin-angiotensin system - Sympathetic nervous system • Prostanoids • Fasudil • L-NAME • Captopril • Guanethidine • Pentolinium • Indomethacin

\section{Corresponding author}

J. Zicha, Institute of Physiology, Czech Academy of Sciences, Vídeňská 1083, 14220 Prague 4, Czech Republic. E-mail: zicha@biomed.cas.cz

\section{Introduction}

The contractile properties of vascular smooth muscle are under dual control of intracellular calcium level and the calcium sensitization of contractile apparatus (Somlyo and Somlyo 2000). Vascular tension is proportional to the amount of phosphorylated myosin (myosin regulatory light chain, MLC20) (Bradley and Morgan 1987, Fujiwara et al. 1989, Himpens et al. 1990). The phosphorylation of MLC20 is under the control of myosin light chain kinase (MLCK) and myosin light chain phosphatase (MLCP). MLCK catalyses phosphorylation and promotes the contractility, while MLCP catalyses the dephosphorylation and lowers vascular contractility. The inhibition of MLCP is known to represent a physiological mechanism to increase vascular contractility. This was observed in response to stimulation of vascular $\alpha_{1}$-adrenergic receptors by phenylephrine (Kitazawa et al. 1991a,b). The increase in vascular contractility, which is not caused by the increased intracellular calcium concentration, is called 
calcium sensitization and it is mediated by the pathway involving Rho-kinase.

Rho-kinase is stimulated by agonist activation of their membrane receptors coupled to $G$ proteins. The Gproteins activate RhoGEFs (guanine nucleotide exchange factors for Rho GTPase), which leads to the exchange of GDP for GTP on the regulatory protein RhoA (Suzuki et al. 2009). RhoA then translocates to the plasma membrane and activates the Rho-kinase (Amano et al. 1996, Ishizaki et al. 1996, Leung et al. 1995). The activated Rho-kinase phosphorylates MLCP, causing its inactivation (Kimura et al. 1996).

Calcium sensitization mediated by the Rhokinase constitutes an important part of vascular contractility control. The alterations of calcium sensitization influence the peripheral resistance of the cardiovascular system and blood pressure (BP). Calcium sensitization was reported to be altered in various forms of genetic hypertension (Uehata et al. 1997, Jin et al. 2006, Ying et al. 2004, Behuliak et al. 2013), the observed changes being dependent on the conditions under which it was measured. Spontaneously hypertensive rats (SHR) and Dahl salt-sensitive rats are the examples of genetic hypertension occurring either spontaneously or under the conditions of excess salt intake. However, the two models differ in the contribution of Rho-kinase-mediated calcium sensitization to hypertension maintenance. When studied following the blockade of endogenous SNS, SHR are characterized by the attenuation of calcium sensitization compared to their normotensive WKY controls (Behuliak et al. 2013), whereas the opposite can be seen in Dahl salt-sensitive rats (Behuliak et al., unpublished data). On the other hand, increased BP response to acute fasudil administration was found in both forms of hypertension when studied in the presence of their enhanced SNS activity (Zicha et al. 2001, Paulis et al. 2007).

The alterations of calcium sensitization can also contribute to BP elevation in non-genetic hypertension models, such as the L-NAME hypertension. This form of hypertension is caused by a lower bioavailability of nitric oxide (NO), which cannot counteract the vasopressor effects of sympathetic nervous system (Sander et al. 1995, Sander et al. 1997, Pecháňová et al. 2004). Sauzeau et al. (2000) described a close connection between the NO-signaling pathway and the Rho-kinase signaling pathway. NO was shown to inhibit RhoA through the activation of cGMP-dependent protein kinase (PKG). The mechanism is physiologically relevant because Chitaley and Webb (2002) described that NO induces vasodilation through Rho-kinase inhibition.

The angiotensin II-dependent hypertension is another experimental model, in which the hypertension development is likely to involve the changes in calcium sensitization. The long-term administration of angiotensin II to normotensive rats leads to the development of severe hypertension. It is known that rats with angiotensin IIdependent hypertension have the upregulated calcium sensitization mediated by Rho-kinase. Jin et al. (2006) observed that isolated aorta of angiotensin IIhypertensive rats is more responsive to Rho-kinase inhibition in comparison with the control. Their study also revealed increased expression of Rho-kinase in the aorta of angiotensin II-hypertensive rats which was later observed in smaller vessels as well (Hilgers et al. 2007).

The aim of the present study was to compare the acute and chronic influence of two most important vasopressor systems - the renin-angiotensin system and the sympathetic nervous system - on calcium sensitization in vascular smooth muscle. Our study also aimed to determine the short-term and long-term effects of NO blockade on calcium sensitization in vascular smooth muscle, as NO is a major opponent of BP changes elicited by RAS and SNS.

\section{Material and Methods}

Male Wistar rats (Institute of Physiology AS CR, Prague, Czech Republic) were housed under standard laboratory conditions. Water and pelleted diet (Altromin, $0.6 \% \mathrm{NaCl}$ ) were provided ad libitum. BP measurements were conducted at the age of 8 to 14 weeks. Blood pressure and heart rate (HR) were recorded in conscious rats using PowerLab system (AD Instruments Ltd., Bella Vista, NSW, Australia). All procedures and experimental protocols were approved by the Ethical Committee of the Institute of Physiology CAS and conform to the European Convention on Animal Protection.

The main experimental approach used in the present study was to measure BP effects of acute Rhokinase blockade by fasudil in rats in which various vasoactive systems were acutely or chronically inhibited. The rats were randomly assigned to experimental or control groups (4-8 rats per group - for experimental groups see Table 1). Cannulation of carotid artery and jugular vein were performed under isoflurane anesthesia $24 \mathrm{~h}$ before BP measurement. On the next day, blood pressure was monitored for $30 \mathrm{~min}$ before the 
administration of the first drug. Thereafter the rats were subjected to a wide range of the acute blockades of particular vasoactive systems (for details see Table 1) before BP response to fasudil was determined. BP changes elicited by the drugs were monitored until blood pressure reached a steady state - 15 min after captopril, $5 \mathrm{~min}$ after pentolinium, $10 \mathrm{~min}$ after L-NAME or indomethacin, and 5 min after each fasudil dose. Fasudil was administered in four cumulative doses $(1 \mathrm{mg} / \mathrm{kg}$, $2 \mathrm{mg} / \mathrm{kg}$, and twice $4 \mathrm{mg} / \mathrm{kg}$ ) (Behuliak et al. 2013). Captopril (angiotensin-converting enzyme inhibitor) was given in a dose of $10 \mathrm{mg} / \mathrm{kg}$, pentolinium (ganglionic blocker) in a dose of $5 \mathrm{mg} / \mathrm{kg}$, NOS inhibitor L-NAME $\left(\mathrm{N}^{\omega}\right.$-nitro-L-arginine methyl ester) in a dose of $30 \mathrm{mg} / \mathrm{kg}$, and indomethacin (cyclooxygenase inhibitor) in a dose of $10 \mathrm{mg} / \mathrm{kg}$ (Zicha et al. 2006, Behuliak et al. 2011).

Chronic inhibition of different vasoactive systems was performed in Groups 7 to 11 (Table 1). Chronic inhibition of the renin-angiotensin system (Group 7) was conducted using the administration of angiotensin-converting enzyme inhibitor captopril (50 mg/kg/day) in drinking water for two weeks. Chronic NOS inhibition (Group 8) was induced by L-NAME (40 mg/kg/day in the drinking fluid for two weeks). These drug treatments lasted until BP measurement at the age of 14 weeks. The sympathectomy by early guanethidine administration was induced in Group 9 (50 mg/kg s.c. on days 7-28 of age) (Johnson et al. 1976).
These sympathectomized rats were measured 6-8 weeks after the end of drug treatment. In Groups 10 and 11 the rats were administered guanethidine for 14 days starting at the age of 3 months and the effects of late guanethidine treatment $(25 \mathrm{mg} / \mathrm{kg}$, i.p.) were studied immediately after the end of drug treatment. To exclude a possible SNS regeneration in these rats, we measured $\mathrm{BP}$ response to intravenous pentolinium $(5 \mathrm{mg} / \mathrm{kg})$ and tyramine $(0.1,0.2$ and $1.0 \mathrm{mg} / \mathrm{kg}$ ) (Douglas et al. 1975).

Several control (CTRL) groups were formed to match the experimental groups by age and body weight. There was a common control group (CTRL-1) for experimental Groups 1 to 6 (the acute inhibition of vasoactive systems). Another control group (CTRL-2) was used for rats with chronic RAS inhibition (captopril) and chronic NOS inhibition (L-NAME), while there were separate age-matched control groups (CTRL-3 and CTRL-4) for rats treated with guanethidine (either in youth or in adulthood).

All drugs and chemicals were purchased at Sigma (St. Louis, MO, USA) except for fasudil (HA-1077, LC Laboratories, Woburn, MA, USA). Drugs were dissolved in saline and usually given as intravenous bolus $(1 \mathrm{ml} / \mathrm{kg})$.

Data were expressed as means \pm SEM. The statistical differences were evaluated by two-way analysis of variance (group and dose as factors) which was followed by the Bonferroni test.

Table 1. The experimental groups in which BP response to dose-dependent fasudil was studied.

\begin{tabular}{|c|c|c|c|c|c|}
\hline \multirow{2}{*}{$\begin{array}{l}\text { Group } \\
1\end{array}$} & \multirow[t]{2}{*}{ Chronic drug treatment } & \multicolumn{4}{|c|}{ Acute drug pretreatment } \\
\hline & & & & L-NAME & \\
\hline 2 & & & & & INDO \\
\hline 3 & & CAPTO & PENTO & L-NAME & \\
\hline 4 & & CAPTO & PENTO & & INDO \\
\hline 5 & & & PENTO & L-NAME & \\
\hline 6 & & САРТO & & L-NAME & \\
\hline 7 & CAPTOPRIL & & & & \\
\hline 8 & $L-N A M E$ & & & & \\
\hline 9 & GUANETHIDINE Early & & & & \\
\hline 10 & GUANETHIDINE Late & & & & \\
\hline 11 & GUANETHIDINE Late & CAPTO & PENTO & L-NAME & \\
\hline
\end{tabular}

CAPTO - captopril, angiotensin-converting enzyme inhibitor; INDO - indomethacin, cyclooxygenase inhibitor; L-NAME - N ${ }^{\omega}$-nitro-Larginine methyl ester, NO synthase inhibitor; PENTO - pentolinium, ganglionic blocker. 


\section{Results}

The effects of acute inhibition of vasodilator systems on calcium sensitization

Rats were acutely pretreated by either NOS inhibitor L-NAME (Group 1) or cyclooxygenase (COX) inhibitor indomethacin (Group 2) before the dosedependent administration of Rho-kinase inhibitor fasudil. Both pretreatments increased blood pressure: acute L-NAME administration caused the elevation of mean arterial pressure (MAP) by $38 \pm 2 \mathrm{~mm} \mathrm{Hg}$, whereas indomethacin elevated MAP only by $8 \pm 3 \mathrm{~mm} \mathrm{Hg}$. Acute NOS inhibition enhanced MAP response to smaller doses of fasudil (Fig. 1, left panel). On the other hand, greater HR rise after fasudil was seen in this group at the highest dose of fasudil (172 \pm 14 beat/min in Group 1 compared to $110 \pm 27$ beat $/ \mathrm{min}$ in controls, $\mathrm{p}<0.05)$. No changes in MAP or HR responses to fasudil were seen after COX inhibition (Group 2) compared to controls (Fig. 1, right panel).
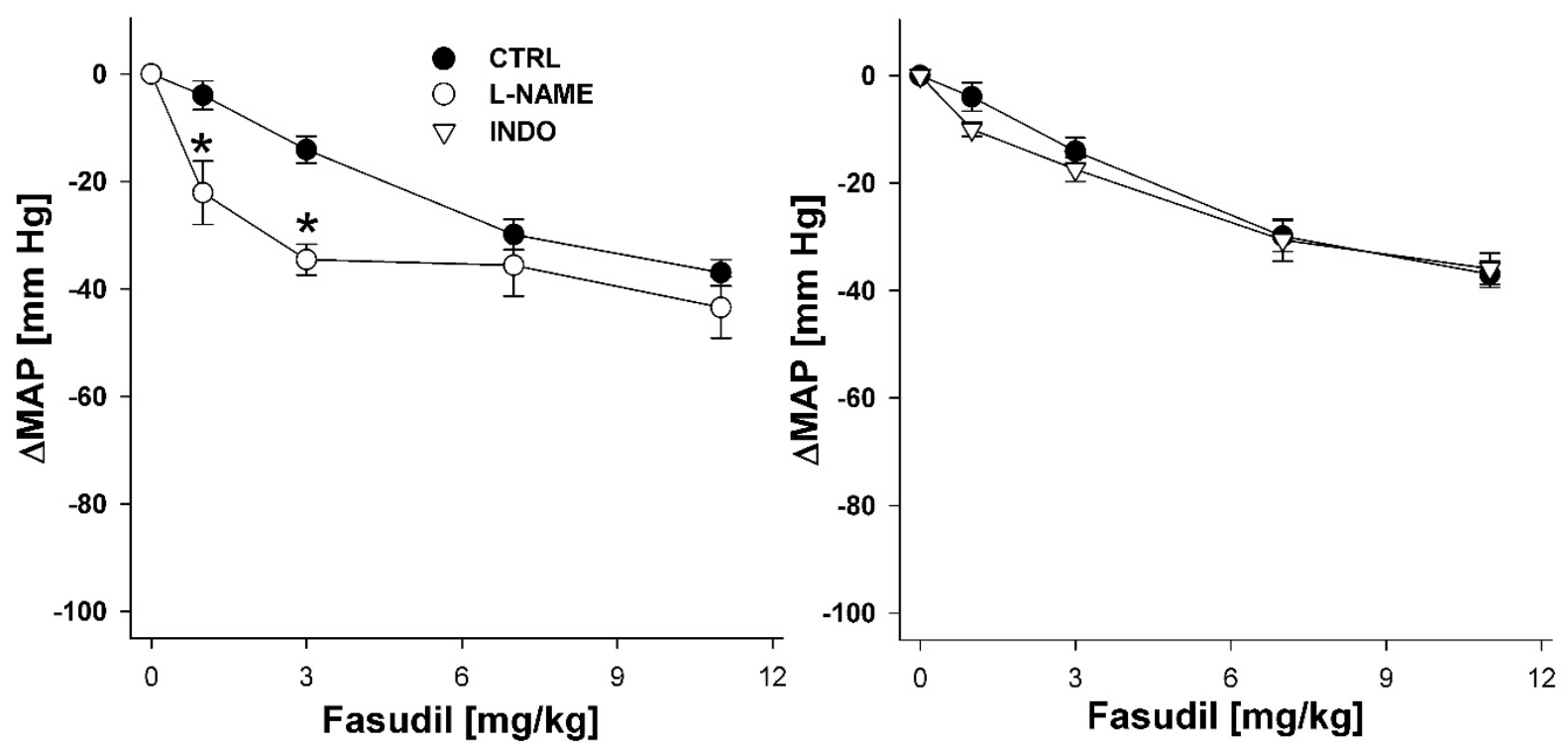

Fig. 1. The influence of NOS inhibition by pretreatment with L-NAME (Group 1, left panel) or COX inhibition by pretreatment with indomethacin (INDO) (Group 2, right panel) on BP changes elicited by fasudil in intact rats ( $\mathrm{n}=4-6$ per group). Mean arterial pressure (MAP) before fasudil administration was $122 \pm 4 \mathrm{~mm} \mathrm{Hg}$ in CTRL-1, $151 \pm 4 \mathrm{~mm} \mathrm{Hg}$ in L-NAME-pretreated rats, and $132 \pm 4 \mathrm{~mm} \mathrm{Hg}$ in indomethacin-pretreated rats. * significant difference $(\mathrm{p}<0.05)$ between the groups. Two-way ANOVA analysis for groups: left panel $F(1,32)=19.8 ; p<0.001 ;$ right panel $F(1,40)=1.42(N S)$.

In order to reveal the full extent of fasudilinduced BP changes in rats subjected to acute NOS or COX inhibition, the possible compensatory influence of principal vasopressor systems (RAS and SNS) were eliminated by captopril and pentolinium administered prior to L-NAME or indomethacin pretreatment (Groups 3 and 4). Under these conditions MAP response to fasudil was greatly enhanced compared to that seen in animals with intact RAS and SNS (Groups 1 and 2). MAP response to fasudil was more augmented in rats with NOS inhibition than in those with COX inhibition (Fig. 2, left panel). The difference between Groups 3 and 4 can also be seen when MAP changes were expressed in percentage of initial MAP prior to fasudil administration $(-56.5 \pm 1.1 \%$ vs. $-42.0 \pm 3.6 \%, \mathrm{p}<0.01)$. No significant differences in HR response to fasudil were observed between Groups 3 and 4, but HR response to fasudil was considerably attenuated by ganglionic blockade in both groups compared to corresponding rats with intact RAS and SNS (Groups 1 and 2) (Fig. 2, right panel).

The effects of acute inhibition of vasoconstrictor systems on calcium sensitization

In order to assess the role of vasoconstrictor systems in short-term regulation of calcium sensitization we took a closer look at the effects of acute inhibition of renin-angiotensin system (RAS) and sympathetic nervous system (SNS). We blocked either SNS (Group 5) or RAS (Group 6) before the acute NOS inhibition by L-NAME (Fig. 3) to increase their blood pressure because BP effect of Rho-kinase inhibition cannot be seen in animals subjected to severe BP lowering by pentolinium. We therefore compared fasudil-induced MAP response of these two groups with that found in L-NAME-pretreated 
rats (Group 1). There were no significant differences among the three studied groups in MAP level recorded before fasudil administration, whereas HR was moderately increased in Group 5 (321 16 beat $/ \mathrm{min})$ as compared to Groups 6 and $1(272 \pm 18$ and $255 \pm 20$ beats/min, respectively). Group 5 (rats deprived of the endogenous SNS) showed an enhanced BP response to fasudil in comparison with L-NAME-pretreated Group 1
(Fig. 3, left panel). This was accompanied by a significantly smaller HR response to fasudil $(34 \pm 14$ beat $/ \mathrm{min}$ in Group 5 as compared to $172 \pm 14$ beat $/ \mathrm{min}$ in L-NAME-pretreated Group 1, $\mathrm{p}<0.001)$. On the contrary, Group 6 (rats deprived acutely of the endogenous RAS) showed no difference in MAP or HR responses to fasudil in comparison with L-NAME-pretreated Group 1 (Fig. 3, right panel).
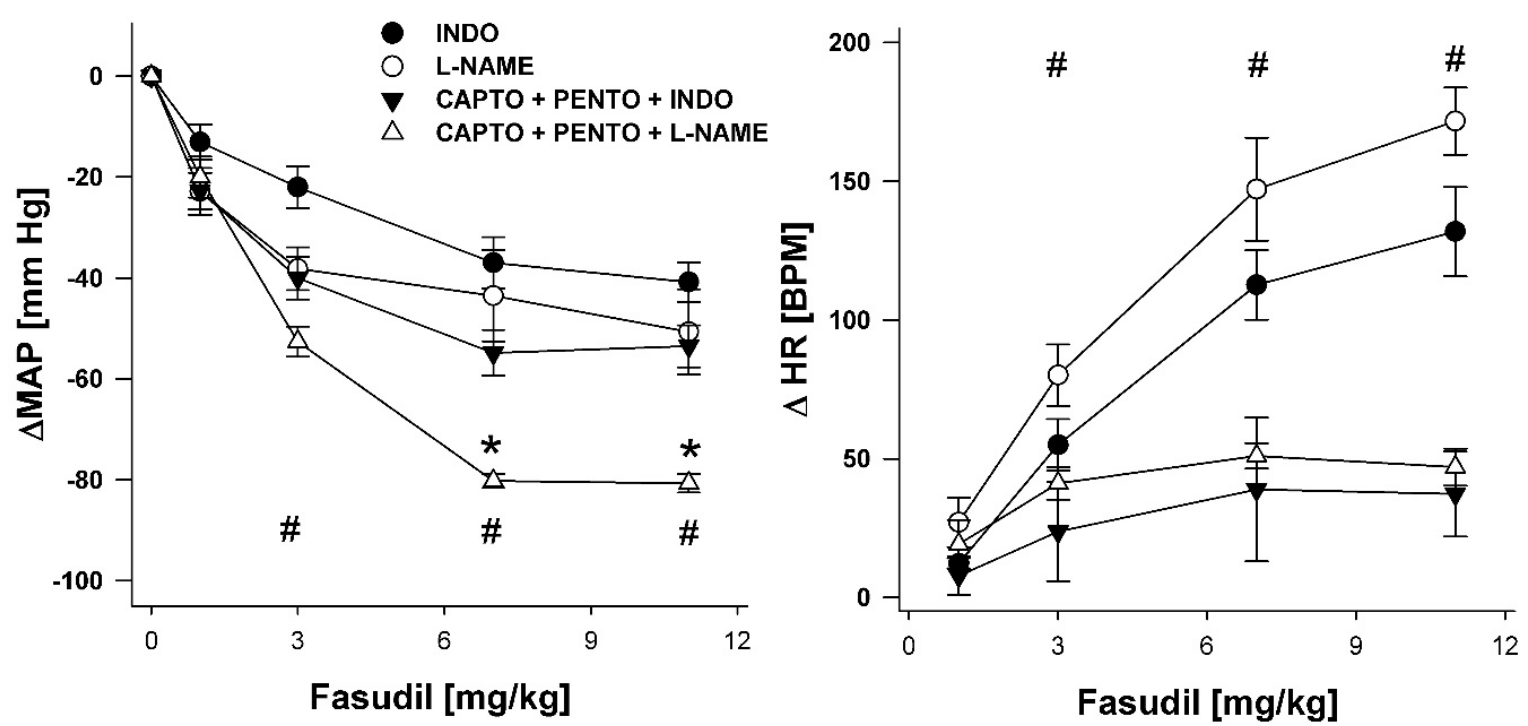

Fig. 2. The influence of acute NOS inhibition by L-NAME (Groups 1 and 3) or acute COX inhibition by indomethacin (Groups 2 and 4) on BP changes (left panel) and HR changes (right panel) elicited by fasudil before (Groups 1 and 2) and after the acute inhibition of RAS by captopril (CAPTO) and SNS by pentolinium (PENTO) (Groups 3 and 4 ) ( $n=5-8$ per group). MAP before fasudil administration was $152 \pm 1 \mathrm{~mm} \mathrm{Hg}$ in CAPTO + PENTO + L-NAME rats (Group 3) and $118 \pm 6 \mathrm{~mm} \mathrm{Hg}$ in CAPTO + PENTO + INDO rats (Group 4). * significant difference $(p<0.01)$ between Groups 3 and 4 , \# significant differences $(p<0.01)$ between Groups 1 and 3 as well as between Groups 2 and 4. Two-way ANOVA analysis for groups: left panel $F(3,76)=53.4, p<0.001$.
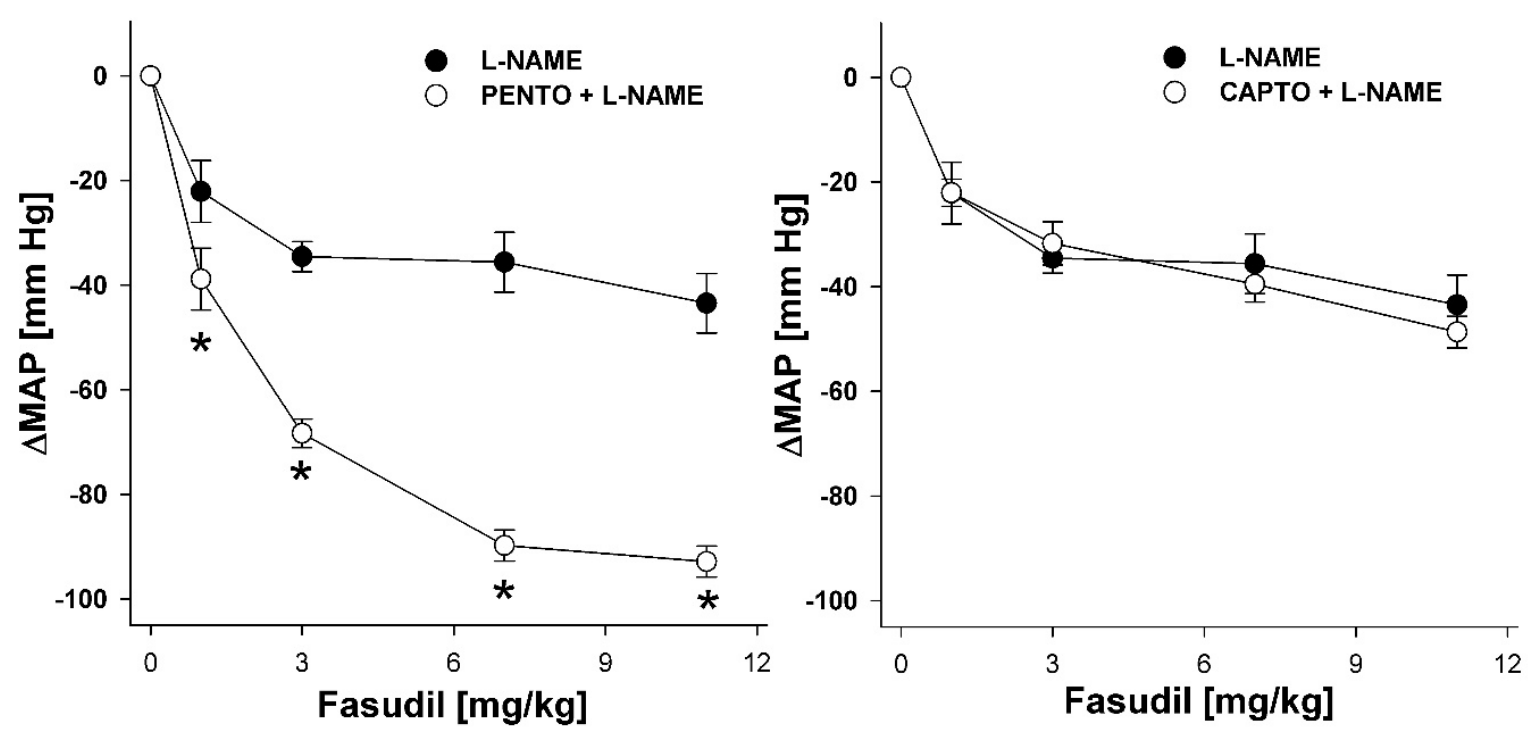

Fig. 3. The influence of pentolinium (Group 5 vs. Group 1, left panel) or captopril pretreatment (Group 6 vs. Group 1, right panel) on BP changes elicited by fasudil under the conditions of acute NOS inhibition ( $n=4-5$ per group). MAP before fasudil administration was $151 \pm 4 \mathrm{~mm} \mathrm{Hg}$ in L-NAME-pretreated rats (Group 1), $157 \pm 3 \mathrm{~mm} \mathrm{Hg}$ in PENTO + L-NAME rats and $152 \pm 2 \mathrm{~mm}$ Hg in CAPTO + L-NAME rats. * significant difference $(p<0.001)$ between the groups. Two-way ANOVA analysis for groups: left panel $F(1,36)=186.5, p<0.001$; right panel $F(1,24)=0.26(N S)$. 


\section{Chronic inhibition of major vasoactive systems}

The chronic inhibition of selected vasoactive systems was conducted to evaluate the long-term contribution of these systems to calcium sensitization. The long-term inhibition of these systems resulted in significant changes of basal BP. Chronic RAS blockade by captopril (Group 7) lowered MAP (105 $\pm 3 \mathrm{~mm} \mathrm{Hg}$ compared to $114 \pm 2 \mathrm{~mm} \mathrm{Hg}$ in CTRL-2 controls, $\mathrm{p}<0.05)$. The long-term captopril administration resulted in a pronounced attenuation of MAP response to fasudil $(-20 \pm 2 \mathrm{~mm} \mathrm{Hg}$ compared to $-32 \pm 2 \mathrm{~mm} \mathrm{Hg}$ in controls, $\mathrm{p}<0.005$ ) (Fig. 4, left panel). This was also true for the relative MAP changes $(-19 \pm 2 \%$ compared to $-28 \pm 2 \%$ in CTRL-2, $\mathrm{p}<0.01)$.
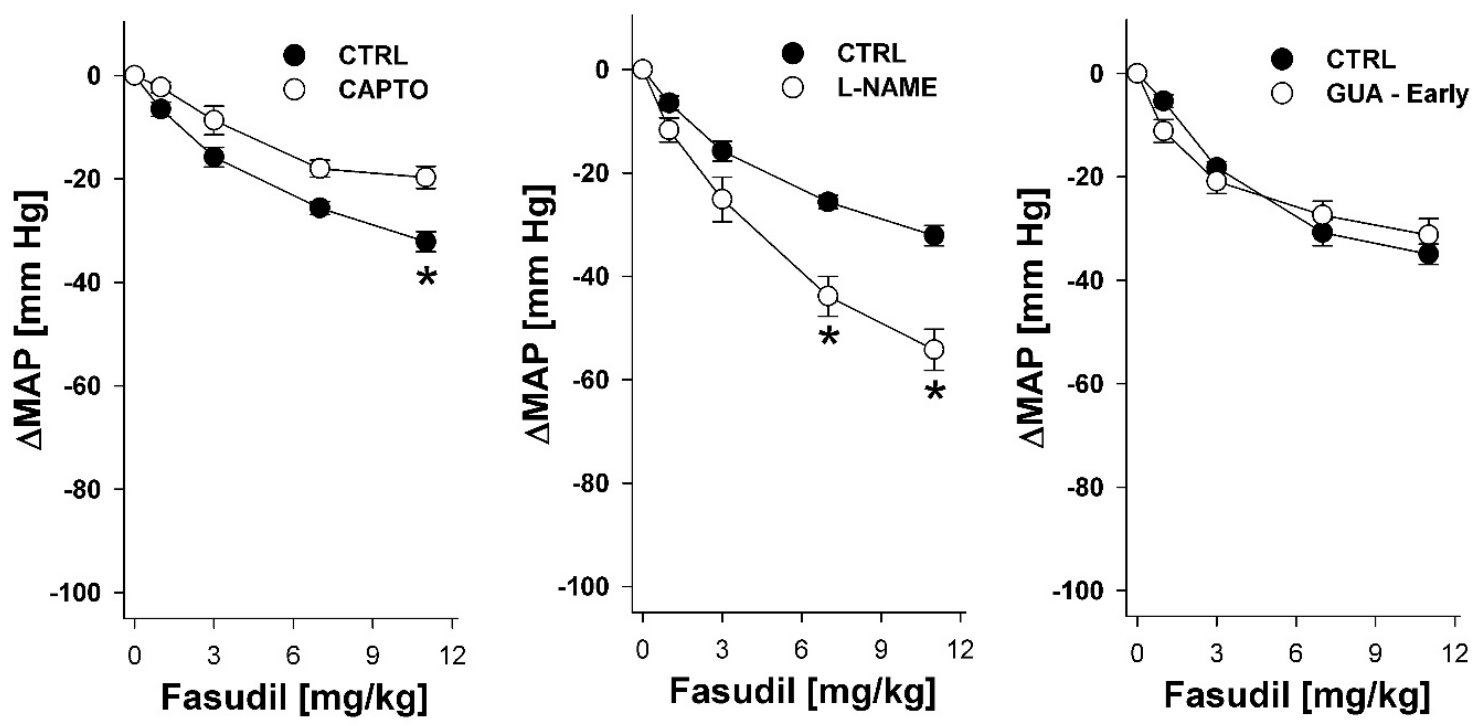

Fig. 4. The influence of chronic RAS inhibition by captopril (Group 7, left panel), chronic NOS inhibition by L-NAME (Group 8, middle panel) and guanethidine-induced early sympathectomy (Group 9, right panel) on BP changes elicited by fasudil ( $n=6-8$ per group). MAP before fasudil administration was $114 \pm 2 \mathrm{~mm} \mathrm{Hg}$ in CTRL-2 and $105 \pm 3 \mathrm{~mm} \mathrm{Hg}$ in captopril-treated rats (left panel); $114 \pm 2 \mathrm{~mm} \mathrm{Hg}$ in CTRL-2 and $142 \pm 3 \mathrm{~mm} \mathrm{Hg}$ in L-NAME-treated rats (middle panel); $122 \pm 3 \mathrm{~mm} \mathrm{Hg}$ in CTRL-3 and $102 \pm 4 \mathrm{~mm} \mathrm{Hg}$ in guanethidine (GUA)-treated rats (right panel). * significant difference $(p<0.001)$ between the groups. Two-way ANOVA analysis for groups: left panel $F(1,52)=37.4(p<0.001)$; middle panel $F(1,56)=50.1(p<0.001)$; right panel $F(1,44)=0.047(N S)$.
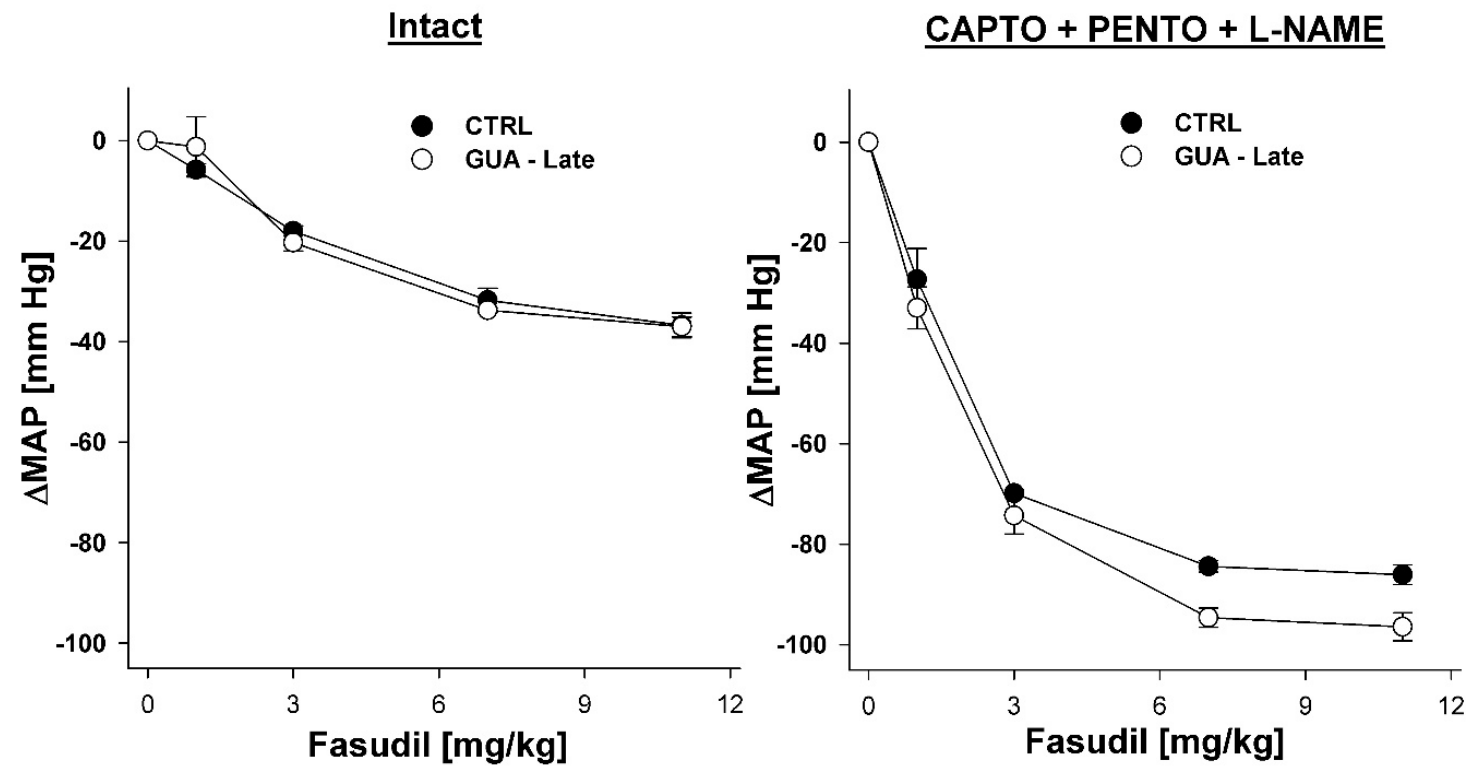

Fig. 5. The influence of late guanethidine-induced catecholamine depletion in adult rats on BP changes elicited by fasudil prior (Group 10, left panel) and after (Group 11, right panel) acute combined RAS, SNS and NOS inhibition ( $n=5-8$ per group). MAP before fasudil administration was $150 \pm 1 \mathrm{~mm} \mathrm{Hg}$ in CTRL-4 and $161 \pm 2 \mathrm{~mm} \mathrm{Hg}$ in rats subjected to late guanethidine (GUA) treatment. Two-way ANOVA analysis for groups: right panel $F(1,16)=8.52(p<0.01)$. 
On the other hand, long-term NOS inhibition by L-NAME (Group 8 ) resulted in BP elevation $(142 \pm 3 \mathrm{~mm}$ $\mathrm{Hg}$ compared to $114 \pm 2 \mathrm{~mm} \mathrm{Hg}$ in CTRL-2 controls, $\mathrm{p}<0.001$ ). Chronic NOS inhibition (Group 8) resulted in a marked enhancement of MAP response to fasudil ( $-55 \pm 5$ compared to $-32 \pm 2 \mathrm{~mm} \mathrm{Hg}$ in CTRL-2, $\mathrm{p}<0.001$ ) (Fig. 4, middle panel), which can also be seen when MAP response was expressed in percentages of MAP values before fasudil administration $(-38 \pm 3 \%$ compared to $-28 \pm 2 \%$ in CTRL-2, $\mathrm{p}<0.01)$. The effect of long-term inhibition of the vasodilator NO system is thus opposite to the effect seen after the long-term inhibition of vasopressor renin-angiotensin system.

The early sympathectomy by guanethidine (Group 9) decreased MAP to $102 \pm 4 \mathrm{~mm} \mathrm{Hg}$ as compared to $122 \pm 3 \mathrm{~mm} \mathrm{Hg}$ in CTRL-3 controls $(\mathrm{p}<0.005)$ and the same was true for late guanethidine treatment (Groups 10 and 11) $(108 \pm 2 \mathrm{~mm} \mathrm{Hg}$ compared to $125 \pm 2 \mathrm{~mm} \mathrm{Hg}$ in CTRL-4 controls, $\mathrm{p}<0.001$ ). The early sympathectomy (Group 9) had no effect on MAP response (Fig. 4, right panel) or HR response ( $92 \pm 19$ compared to $96 \pm 7$ beats $/ \mathrm{min}$ in controls) to acute fasudil administration. To evaluate the degree of sympathectomy we administered pentolinium and tyramine to the same rats. MAP response of sympathectomized rats to acute ganglionic blockade by pentolinium was lowered by $70 \%$, whereas the acute MAP response to norepinephrine released from the nerve endings by tyramine was decreased by $60-70 \%$. Although some signs of effective early sympathectomy were still present, there was a considerable recovery of SNS during two months after guanethidine withdrawal.

The chronic guanethidine treatment of adult rats (Group 10) did not influence significantly MAP response to acute fasudil administration, the response being similar to that of rats subjected to early sympathectomy (Fig. 5, left panel). BP response to acute ganglionic blockade was also substantially reduced by $70 \%$ in rats subjected to late guanethidine treatment. BP response to tyramine administration was also diminished by $80 \%$. Figure 5 (right panel) shows that under the conditions of combined RAS, SNS and NOS blockade (Group 11) there were no major differences in MAP response to acute fasudil administration between guanethidine-treated rats and their CTRL-4 controls.

\section{Discussion}

The present study extends our knowledge about the involvement of calcium sensitization in blood pressure maintenance. Principal vasoactive systems were shown to influence the blood pressure component dependent on calcium sensitization in a different manner. The acute inhibition of nitric oxide synthase (NOS) by L-NAME caused the enhancement of BP response to Rho-kinase inhibitor fasudil. In contrast, there was no effect of the acute cyclooxygenase (COX) inhibition by indomethacin on $\mathrm{BP}$ response to fasudil. The acute inhibition of sympathetic nervous system (SNS) and renin-angiotensin system (RAS) (studied under the conditions of a concurrent NOS or COX inhibition) enhanced BP response to fasudil but this effect can be ascribed to the lack of baroflex operation (see below) rather than to the changes in calcium sensitization.

A chronic inhibition of particular vasoactive systems had often quite different effects on calcium sensitization than the acute inhibition of these systems (RAS, SNS and NOS). Long-term administration of angiotensin-converting enzyme inhibitor captopril attenuated BP response to fasudil. In contrast, no effect of early or late guanethidine treatment (leading to a profound catecholamine depletion in nerve endings) on calcium sensitization was observed. The enhancement of BP response to fasudil in chronically L-NAME-treated rats exceeded the effect of acute NOS inhibition.

The evidence has been accumulating that calcium sensitization is influenced by NO acting on vascular smooth muscle cells. Sauzeau et al. (2000) described that NO inhibits RhoA through the activation of cGMP-dependent protein kinase (PKG). In the present study we demonstrated that the acute NOS inhibition augmented BP reduction after acute Rho-kinase inhibition. Further experiment indicated that the enhancement of BP response to fasudil after acute L-NAME administration was preserved even in the absence of major vasopressor systems (RAS and SNS). Moreover, chronic NOS inhibition increased BP and enhanced BP response to acute Rho-kinase inhibition. This effect of chronic L-NAME administration can also be seen if BP response to fasudil is expressed in percentage of blood pressure recorded before the acute fasudil administration. This excludes a possibility that the observed effect is due to the general L-NAME-induced increase in blood pressure. Thus, calcium sensitization is suppressed by NO in vascular smooth muscle of normotensive rats and it is enhanced under the conditions of low NO bioavailability.

We suppose that $\mathrm{NO}$ occupies a prominent position in blood pressure regulation, because it can 
oppose the effects of angiotensin II on calcium sensitization. L-NAME hypertension develops partially due to RAS dysregulation, which is evidenced by the increased cardiac and aortic activity of angiotensinconverting enzyme (Takemoto et al. 1997). L-NAME hypertensive rats also have the increased Rho-kinase activity, which can be prevented by chronic inhibition of angiotensin $\mathrm{AT}_{1}$ receptor (AT1R) (Kataoka et al. 2002). These findings point to a strong interrelationship of $\mathrm{NO}$ and angiotensin II signaling.

In contrast to NOS inhibition, the acute COX inhibition by indomethacin did not affect BP response to fasudil in intact rats. Teixeira et al. (2005) described that the inhibition of cyclooxygenase does not affect vasodilator response of phenylephrine-precontracted isolated arteries to Rho-kinase inhibition. This is in line with our findings. The comparison of BP response to fasudil in L-NAME-pretreated or indomethacinpretreated rats, which were deprived of endogenous vasopressor systems (SNS and RAS), shows a greater BP response to fasudil in L-NAME-pretreated group.

The in vitro studies suggest that the activation of angiotensin or adrenergic receptors in vascular smooth muscle rapidly augments calcium sensitization in vascular smooth muscle. Tsai and Jiang (2006) reported that the activation of $\alpha_{1}$-adrenergic receptors enhanced calcium sensitization mediated by the Rho-kinase pathway. AT1R activation also increased calcium sensitization in vascular smooth muscle (Somlyo and Somlyo 2003). These vasopressor systems can also exert long-term effects on calcium sensitization, mediated by the changes in gene expression patterns. The increased protein expression of Rho-kinase and a greater response to Rho-kinase inhibition were observed in the isolated aorta of rats with angiotensin II-induced hypertension compared to controls (Jin et al. 2006). Yamakawa et al. (2000) suggested that the Rho-kinase pathway mediates the upregulation of the proteins of contractile machinery, which was observed in vascular smooth muscle cells exposed to increased angiotensin II levels. Puzdrova et al. (2014) suggested that trophic action of sympathetic nerves reduced calcium sensitization in arterial smooth muscles. To determine the relative contributions of RAS and SNS to vascular smooth muscle calcium sensitization and blood pressure maintenance, we studied BP response of conscious rats to acute Rho-kinase inhibition under the conditions of both acute and chronic inhibition of either RAS or SNS.

The acute RAS inhibition by captopril did not cause any significant change in BP response to fasudil in either intact animals or rats subjected to RAS and SNS blockade. However, physiological levels of angiotensin II in normotensive rats need not be high enough to be compared with angiotensin II concentrations used in vitro. In fact, Hojná et al. (unpublished data) observed that acute fasudil administration considerably attenuated BP response to injected angiotensin II. On the other hand, we observed that chronic RAS inhibition caused a mild $\mathrm{BP}$ decrease and a reduction of BP response to fasudil. The attenuation of BP response to fasudil cannot be ascribed to the decreased BP of captopril-treated rats because this effect was preserved even if BP changes were expressed in the percentage of blood pressure recorded before fasudil administration. We can conclude that under the in vivo conditions calcium sensitization in vascular smooth muscle of normotensive rats is enhanced by long-term (but not short-term) action of angiotensin II.

The acute SNS inhibition in rats subjected to acute NOS inhibition was accompanied by a marked enhancement of BP response to fasudil. This unexpected effect can be explained by the abolishment of sympathetic nerve activity which is triggered by the activation of arterial baroreflex during fasudil-induced BP decrease. The ganglionic blockade by pentolinium abolishes both the increase in heart rate and cardiac output (mediated by $\beta$-adrenoceptor stimulation) and the rise of $\alpha$-adrenergic vasoconstriction. Both changes contribute to the attenuation of fasudil-induced BP decrease observed in rats with intact SNS. The SNS plays a very important role in the differentiation of vascular smooth muscle cells and in the development of normal blood vessels. It may also be involved in developmental changes of calcium sensitization. Puzdrova et al. (2014) reported that calcium sensitivity of vascular contractions to vasoconstrictors methoxamine ( $\alpha_{1}$-adrenergic receptor agonist) and U46619 (thromboxane $\mathrm{A}_{2}$ receptor agonist) decreases during the early postnatal development. The denervation of blood vessels can restore a high calcium sensitivity in adult animals. They also described a lower Rho-kinase expression in arteries of adult animals compared to young ones. However, no differences in Rho-kinase expression or in the contractile response to Rho-kinase inhibition were found in arteries of adult sympathectomized rats compared to those of age-matched intact rats. The authors suggest that a long-term sympathectomy may be needed for a change in Rho-kinase expression to occur (Puzdrova et al. 2014). However, in our experiments neither the sympathectomy 
induced by early guanethidine administration nor catecholamine deletion elicited by guanethidine treatment in adulthood caused any significant changes in BP response to fasudil. Thus, our results suggest that Rho-kinase-mediated calcium sensitization was not altered in sympathectomized rats.

In conclusion, the balance of angiotensin II and nitric oxide is important for the control of calcium sensitization in vascular smooth muscle. NO seems to affect calcium sensitization in a rapid manner because the effects of acute NOS inhibition on BP response to fasudil are seen within minutes after L-NAME administration. On the contrary, the effects of RAS on calcium sensitization are rather long-term because the chronic (but not the acute) RAS blockade lowers blood pressure and attenuates BP response to fasudil in normotensive animals. The low NO bioavailability in L-NAME hypertension leads to the increased calcium sensitization, which significantly contributes to hypertension maintenance.

\section{Conflict of Interest}

There is no conflict of interest.

\section{Acknowledgements}

This study was partially supported by research grants RVO:67985823, GACR 304/12/0259 and AZV 15-25396A (Agency for Medical Research of the Czech Republic). The skillful assistance of Mrs. Zdenka Kopecká and Mrs. Iva Nahodilová is greatly appreciated.

\section{References}

AMANO M, ITO M, KIMURA K, FUKATA Y, CHIHARA K, NAKANO T, MATSUURA Y, KAIBUCHI K: Phosphorylation and activation of myosin by Rho-associated kinase (Rho-kinase). J Biol Chem 271: 2024620249, 1996.

BEHULIAK M, PINTÉROVÁ M, KUNEŠ J, ZICHA J: Vasodilator efficiency of endogenous prostanoids, Ca ${ }^{2+}$ activated $\mathrm{K}^{+}$channels and nitric oxide in rats with spontaneous, salt-dependent or NO-deficient hypertension. Hypertens Res 34: 968-975, 2011.

BEHULIAK M, PINTÉROVÁ M, BENCZE M, PETROVÁ M, LIŠKOVÁ S, KAREN P, KUNEŠ J, VANĚČKOVÁ I, ZICHA J: $\mathrm{Ca}^{2+}$ sensitization and $\mathrm{Ca}^{2+}$ entry in the control of blood pressure and adrenergic vasoconstriction in conscious Wistar-Kyoto and spontaneously hypertensive rats. J Hypertens 31: 2025-2035, 2013.

BRADLEY AB, MORGAN KG: Alterations in cytoplasmic calcium sensitivity during porcine coronary-artery contractions as detected by aequorin. J Physiol (London) 385: 437-448, 1987.

CHITALEY K, WEBB RC: Nitric oxide induces dilation of rat aorta via inhibition of Rho-kinase signaling. Hypertension 39: 438-442, 2002.

DOUGLAS JR JR, JOHNSON EM JR, MARSHALL GR, HEIST J, HARTMAN BK, NEEDLEMAN P: Development and maintenance of renal hypertension in normal and guanethidine sympathectomized rats. Circ Res 36 (Suppl I): I-171-I-178, 1975.

FUJIWARA T, ITOH T, KUBOTA Y, KURIYAMA H: Effects of guanosine nucleotides on skinned smooth muscle tissue of the rabbit mesenteric artery. J Physiol (London) 408: 535-547, 1989.

HILGERS RHP, TODD J, WEBB RC: Increased PDZ-RhoGEF/RhoA/Rho kinase signaling in small mesenteric arteries of angiotensin II-induced hypertensive rats. J Hypertens 25: 1687-1697, 2007.

HIMPENS B, KITAZAWA T, SOMLYO AP: Agonist-dependent modulation of $\mathrm{Ca}^{2+}$ sensitivity in rabbit pulmonary artery smooth muscle. Pflügers Arch 417: 21-28, 1990.

ISHIZAKI T, MAEKAWA M, FUJISAWA M, OKAWA K, IWAMATSU A, FUJITA A, WATANABE N, SAITO Y, KAKIZUKA A, MORII N, NARUMIYA S: The small GTP-binding protein Rho binds to and activates a 160 $\mathrm{kDa}$ Ser/Thr protein kinase homologous to myotonic dystrophy kinase. EMBO J 15: 1885-1893, 1996.

JIN LM, YING ZK, HILGERS RPH, YIN J, ZHAO XY, IMIG JD, WEBB RC: Increased RhoA/Rho-kinase signaling mediates spontaneous tone in aorta from angiotensin II-induced hypertensive rats. J Pharmacol Exp Ther 318 : 288-295, 2006.

JOHNSON EM JR, O'BRIEN F, WERBITT R: Modification and characterization of the permanent sympathectomy produced by the administration of guanethidine to newborn rats. Eur J Pharmacol 37: 45-54, 1976. 
KATAOKA C, EGASHIRA K, INOUE S, TAKEMOTO M, NI WH, KOYANAGI M, KITAMOTO S, USUI M, KAIBUCHI K, SHIMOKAWA H, TAKESHITA A: Important role of Rho-kinase in the pathogenesis of cardiovascular inflammation and remodeling induced by long-term blockade of nitric oxide synthesis in rats. Hypertension 39: 245-250, 2002.

KIMURA K, ITO M, AMANO M, CHIHARA K, FUKATA Y, NAKAFUKU M, YAMAMORI B, FENG JH, NAKANO T, OKAWA K, IWAMATSU A, KAIBUCHI K: Regulation of myosin phosphatase by Rho and Rho-associated kinase (Rho-kinase). Science 273: 245-248, 1996.

KITAZAWA T, GAYLINN BD, DENNEY GH, SOMLYO AP: G-protein-mediated $\mathrm{Ca}^{2+}$ sensitization of smoothmuscle contraction through myosin light chain phosphorylation. J Biol Chem 266: 1708-1715, 1991 a.

KITAZAWA T, MASUO M, SOMLYO AP: G-protein-mediated inhibition of myosin light-chain phosphatase in vascular smooth-muscle. Proc Natl Acad Sci U S A 88: 9307-9310, 1991b.

LEUNG T, MANSER E, TAN L, LIM L: A novel serine/threonine kinase binding the Ras-related RhoA GTPase which translocates the kinase to peripheral membranes. J Biol Chem 270: 29051-29054, 1995.

PAULIS L, LÍŠKOVÁ S, PINTÉROVÁ M, DOBEŠOVÁ Z, KUNEŠ J, ZICHA J: Nifedipine-sensitive noradrenergic vasoconstriction is enhanced in spontaneously hypertensive rats: the influence of chronic captopril treatment. Acta Physiol (Oxford) 191: 255-266, 2007.

PECHÁŇOVÁ O, DOBEŠOVÁ Z, ČEJKA J, KUNEŠ J, ZICHA J: Vasoactive systems in L-NAME hypertension: the role of inducible nitric oxide synthase. J Hypertens 22: 167-173, 2004.

PUZDROVA VA, KUDRYASHOVA TV, GAYNULLINA DK, MOCHALOV SV, AALKJAER C, NILSSON H, VOROTNIKOV AV, SCHUBERT R, TARASOVA OS: Trophic action of sympathetic nerves reduces arterial smooth muscle $\mathrm{Ca}^{2+}$ sensitivity during early post-natal development in rats. Acta Physiol (Oxford) 212: 128$141,2014$.

SANDER M, HANSEN J, VICTOR RG: The sympathetic nervous system is involved in the maintenance but not initiation of the hypertension induced by $\mathrm{N}^{\omega}$-nitro-L-arginine methyl ester. Hypertension 30: 64-70, 1997.

SANDER M, HANSEN PG, VICTOR RG: Sympathetically mediated hypertension caused by chronic inhibition of nitric oxide. Hypertension 26: 691-695, 1995.

SAUZEAU V, LE JEUNE H, CARIO-TOUMANIANTZ C, SMOLENSKI A, LOHMANN SM, BERTOGLIO J, CHARDIN P, PACAUD P, LOIRAND G: Cyclic GMP-dependent protein kinase signaling pathway inhibits RhoA-induced $\mathrm{Ca}^{2+}$ sensitization of contraction in vascular smooth muscle. J Biol Chem 275: 21722-21729, 2000.

SOMLYO AP, SOMLYO AV: Signal transduction by G-proteins, Rho-kinase and protein phosphatase to smooth muscle and non-muscle myosin II. J Physiol (London) 522: 177-185, 2000.

SOMLYO AP, SOMLYO AV: $\mathrm{Ca}^{2+}$ sensitivity of smooth muscle and nonmuscle myosin II: Modulated by G proteins, kinases, and myosin phosphatase. Physiol Rev 83: 1325-1358, 2003.

SUZUKI N, HAJICEK N, KOZASA T: Regulation and physiological functions of $\mathrm{G}_{12 / 13}$-mediated signaling pathways. Neurosignals 17: 55-70, 2009.

TAKEMOTO M, EGASHIRA K, USUI M, NUMAGUCHI K, TOMITA H, TSUTSUI H, SHIMOKAWA H, SUEISHI $\mathrm{K}$, TAKESHITA A: Important role of tissue angiotensin-converting enzyme activity in the pathogenesis of coronary vascular and myocardial structural changes induced by long-term blockade of nitric oxide synthesis in rats. J Clin Invest 99: 278-287, 1997.

TEIXEIRA CE, JIN LM, YING ZK, PALMER T, PRIVIERO FBM, WEBB RC: Expression and functional role of the RhoA/Rho-kinase pathway in rat coeliac artery. Clin Exp Pharmacol Physiol 32: 817-824, 2005.

TSAI MH, JIANG MJ: Rho-kinase-mediated regulation of receptor-agonist-stimulated smooth muscle contraction. Pflügers Arch 453: 223-232, 2006.

UEHATA M, ISHIZAKI T, SATOH H, ONO T, KAWAHARA T, MORISHITA T, TAMAKAWA H, YAMAGAMI K, INUI J, MAEKAWA M, NARUMIYA S: Calcium sensitization of smooth muscle mediated by a Rhoassociated protein kinase in hypertension. Nature 389: 990-994, 1997.

YAMAKAWA T, TANAKA S, NUMAGUCHI K, YAMAKAWA Y, MOTLEY ED, ICHIHARA S, INAGAMI T: Involvement of Rho-kinase in angiotensin II-induced hypertrophy of rat vascular smooth muscle cells. Hypertension 35: 313-318, 2000. 
YING ZK, JIN LM, DORRANCE AM, WEBB RC: Increased expression of mRNA for regulator of G protein signaling domain-containing Rho guanine nucleotide exchange factors in aorta from stroke-prone spontaneously hypertensive rats. Am J Hypertens 17: 981-985, 2004.

ZICHA J, DOBEŠOVÁ Z, KUNEŠ J: Relative deficiency of nitric oxide-dependent vasodilation in salt hypertensive Dahl rats: the possible role of superoxide anions. J Hypertens 19: 247-254, 2001.

ZICHA J, DOBEŠOVÁ Z, KUNEŠ J: Antihypertensive mechanisms of chronic captopril or N-acetylcysteine treatment in L-NAME hypertensive rats. Hypertens Res 29: 1021-1027, 2006. 